\title{
A New Approach for the Determination of Elastic Property of Urea-Formaldehyde Microcapsules
}

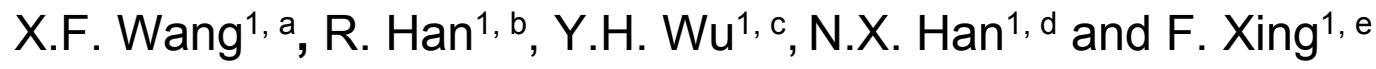 \\ ${ }^{1}$ Guangdong Key Laboratory of Durability in Coastal Civil Engineering, College of Civil Engineering, \\ Shenzhen University, Shenzhen, Guangdong 518060, China \\ axfw@szu.edu.cn, bszuruihan@Yahoo.com, 9wyhszdx@sina.com, dnxhan@szu.edu.cn and \\ exingf@szu.edu.cn
}

Keywords: Microcapsules; Mechanical properties; Nanoindentation.

Abstract. Determination of the mechanical properties of urea-formaldehyde (UF) microcapsules is extremely important. In this study, UF microcapsules were made by using in situ polymerization method. The diameter and thickness of UF microcapsules were characterized by using scanning electron microscopy (SEM). In addition, the elastic property of UF microcapsules, such as Young's modulus, was computed by performing nanoindentation using a diamond plate indenter and plate and shell theory. Results showed that the mean diameter and thickness of the microcapsules were 194.2 $\mu \mathrm{m}$ and $8.3 \mu \mathrm{m}$, respectively. And the mean results of Young's modulus were $0.86 \mathrm{GPa}, 0.66 \mathrm{GPa}$ and $0.73 \mathrm{GPa}$.

\section{Introduction}

Microcapsules filled with core substance encapsulated by an organic or inorganic wall are some small particles, and a single microcapsule is considered to be a kind of core-shell structure. The varieties of core materials and different trigger patterns directly determine the applications of microcapsules. In reality, microcapsules are extensively applied to produce functional materials, including food industry [1], medicine [2] and chemical industry [3], etc. It is crucial to consider the mechanical characteristics of a microcapsule during its design regarding its prospective applications. The two methods of studying mechanical properties of the micro-nano particles are bulk methods and individual methods. For bulk methods, researchers have focused on shear forces [4] and osmotic pressure [5], and tried to extract average mechanical parameters across the batch, such as shear elastic modulus, etc. For individual microcapsule measurements, the recently experimental investigation techniques, including optical or magnetic tweezers [6], shear flow (spinning drop apparatus) [7], atomic force microscope (AFM) [8], nanoindentation [9], etc. were developed. Among these measurement techniques, AFM and nanoindentation are widely applied to study the mechanical properties of core-shell structures. Hertzian half-space contact mechanics model was applied to determine Young's modulus [10]. In this paper, the nanoindentation tests were performed using a diamond plate indenter. The test data was analyzed by combining the elastic solution of concentrated loads on thin spherical shells to optimize Young's modulus by using ordinary least square (OLS) method.

\section{Materials and Experimental Methods}

In this study, the UF microcapsules containing epoxy resin were synthesized using in situ polymerization method. The detailed operation of the synthesis can be found in reference [11]. Table 1 gives the specific parameters of the microcapsules. Fig. Fig. 1a shows an image of the microcapsules with diameter calibration and Fig. Fig. 1b shows an image of microcapsule fragments with thickness calibration. These two parameters were all characterized by using SEM (Quanta TM 250 FEG) for accounting the samples of 300 microcapsules. 
Table 1. UF Microcapsules specific parameters

\begin{tabular}{|c|c|c|c|}
\hline $\begin{array}{c}\text { Rotation } \\
\text { Velocity in } \\
\text { Synthesis }(\mathrm{r} / \mathrm{min})\end{array}$ & $\begin{array}{c}\text { Average } \\
\text { Diameter }(\mu \mathrm{m})\end{array}$ & $\begin{array}{c}\text { Shell Thickness } \\
(\mu \mathrm{m})\end{array}$ & $\begin{array}{c}\text { Capsule Core } \\
\text { Content }(\%)\end{array}$ \\
\hline 200 & 194.2 & 8.3 & 75 \\
\hline
\end{tabular}

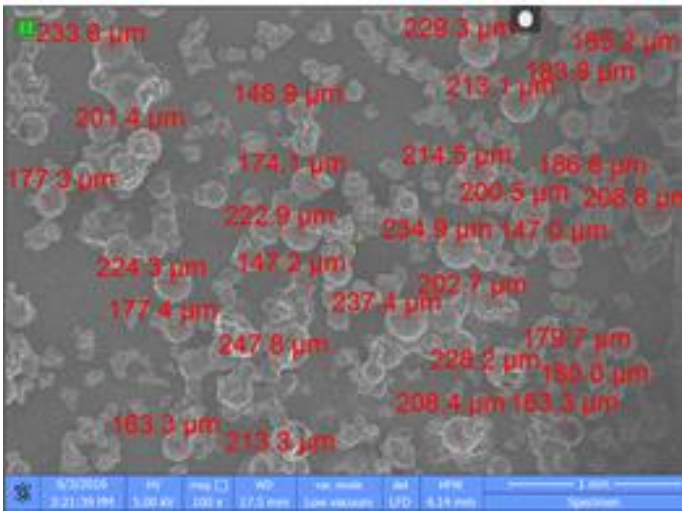

(a)

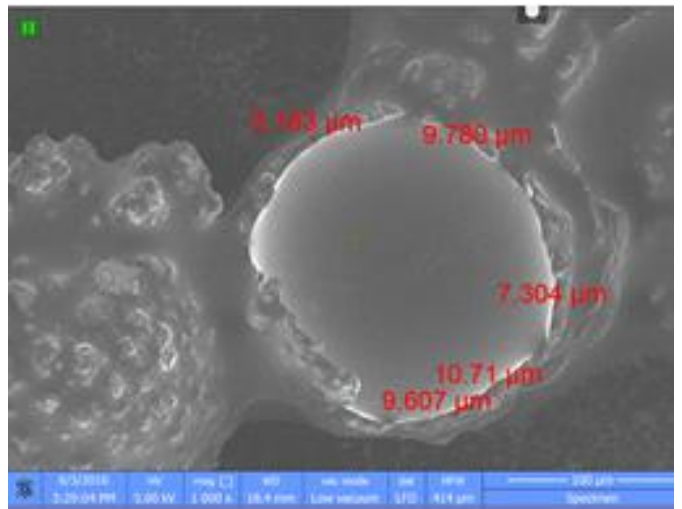

(b)

Fig. 1 (a) SEM images of the microcapaules with diameter calibration, (b) SEM images of the microcapaules with thickness calibration.

The nanoindentation tests were performed on a PI 85 SEM PicoIndenter (HYSITRON Inc., USA) using a Berkovich indenter to obtain the loading-unloading curve under ambient conditions. The maximum displacement and force resolutions are $0.01 \mathrm{~nm}$ and $50 \mathrm{nN}$, respectively. To minimize the time-dependent plastic effect, the load was kept for $10 \mathrm{~s}$ when it reached to the maximum value. Three microcapsules were compressed to $5000 \mathrm{~nm}$ between the two parallel plate surfaces. The three experimental curves were fitted using quadratic functions. The elastic solution of concentrated loads on shallow spherical shells and the fitting function were applied to construct the objective function, from which the optimized Young's modulus of the UF microcapsules was obtained by using OLS method.

\section{Results and Discussions}

The load-displacement curves of three samples obtained from the nanoindentation tests using a plate indenter are shown in Fig. 2. The load applied on the microcapsule initially increased when they were compressed. The responding force is not the same when the displacement reaches the maximum since each sample's thickness is not totally similar. Finally, the three curves were fitted to quadratic polynomial in Table 2 .

The elastic solutions of concentrated loads on the shallow spherical shells developed by Lukasiewicz [12], Reissner [13] and Pogorelov [14] were applied. In addition, it is assumed that the shell is considered as a material of isotropic elasticity that is able to be described by Young's modulus and Poisson ratio v. These elastic solutions are shown by Eq. 1, Eq. 2 and Eq. 3, respectively. And the detailed process of optimization is shown by Eq. 4 and Eq. 5. Finally, the optimization results are shown in Table 3. 


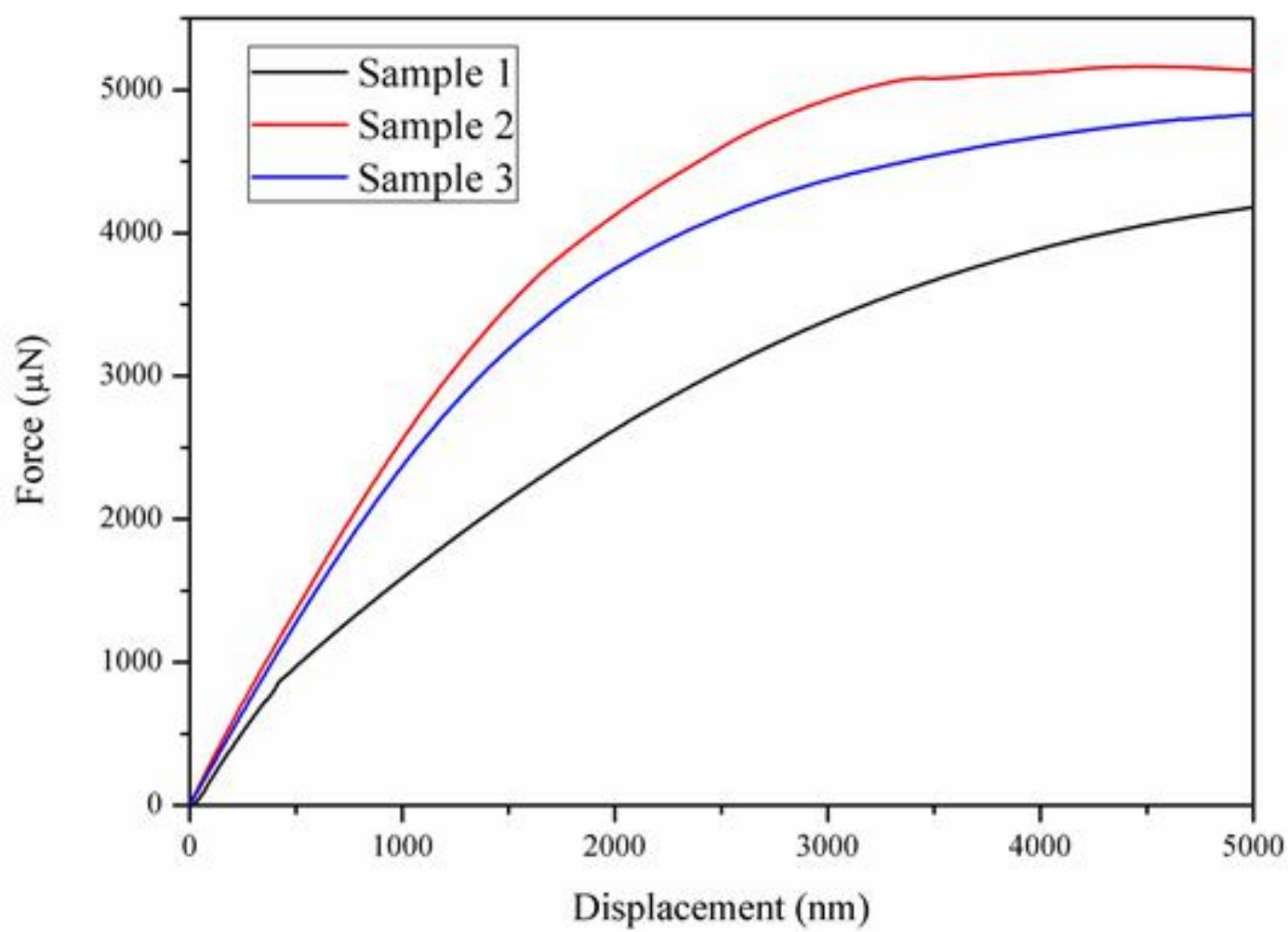

Fig. 2 Force versus displacement curve for compressing three single microcapsules of $200 \mu \mathrm{m}$ in diameter to $5000 \mathrm{~nm}$.

Table 2. The fitting functions

\begin{tabular}{|c|c|c|c|}
\hline Samples & Fitting Functions & Intervals & Re-square \\
\hline 1 & $\mathrm{~F}=-0.00016 \mathrm{~h}^{2}+1.6 \mathrm{~h}$ & {$[0,5000]$} & 0.9974 \\
\hline 2 & $\mathrm{~F}=-0.00034 \mathrm{~h}^{2}+2.6 \mathrm{~h}$ & {$[0,5000]$} & 0.9952 \\
\hline 3 & $\mathrm{~F}=-0.00028 \mathrm{~h}^{2}+2.3 \mathrm{~h}$ & {$[0,5000]$} & 0.9906 \\
\hline
\end{tabular}

$$
\begin{aligned}
& F=\frac{4 E t^{2} h}{\sqrt{3\left(1-v^{2}\right) R}} \\
& F=\sqrt{\frac{3.56 E^{2} t^{5} h}{\left(1-v^{2}\right)^{2} R^{2}}}
\end{aligned}
$$

where $v$ is the Poisson's ratio of the samples; $\mathrm{R}$ is the radius of single microcapsule; $\mathrm{E}$ is the Young's modulus of the measured sample; $t$ is the mean thickness of the microcapsules; and kei[z] is the Kelvin function.

$$
f(E)=\int_{0}^{5000}\left[\left(-0.00016 h^{2}+1.6 h\right)-\left(\frac{4 E t^{2} h}{\sqrt{3\left(1-v^{2}\right) R}}\right)\right]^{2} d h
$$


Table 3. The Optimization Results

\begin{tabular}{|c|c|c|c|}
\hline Samples & $\begin{array}{c}\text { E by Eq. 1 } \\
(\mathrm{GPa})\end{array}$ & $\begin{array}{c}\text { E by Eq. 2 } \\
(\mathrm{GPa})\end{array}$ & $\begin{array}{c}\text { E by Eq. 3 } \\
(\mathrm{GPa})\end{array}$ \\
\hline 1 & 0.90 & 0.68 & 0.75 \\
\hline 2 & 0.88 & 0.67 & 0.73 \\
\hline 3 & 0.81 & 0.62 & 0.71 \\
\hline Mean value & 0.86 & 0.66 & 0.73 \\
\hline
\end{tabular}

\section{Conclusions}

In the present paper, a new method to determine the elastic mechanical parameters of a single microcapsule is proposed, which is by combining shell theory with optimization. the detailed values are $0.86 \mathrm{GPa}, 0.66 \mathrm{GPa}$ and $0.73 \mathrm{GPa}$. In the final analysis, the new proposed approach is valid and effective for determining Young's modulus of core-shell microcapsules based on plate compression tests.

\section{Acknowledgements}

This work was financially supported by the General Program of the National Natural Science Foundation of China (No.51478272), the joint funds of the National Natural Science Foundation and Guangdong Province of China (U1301241), the International Cooperation and Exchange of the National Natural Science Foundation of China (51520105012), the Science and Technology Foundation for the Basic Research Plan of Shenzhen City (JCYJ20160422095146121), and the Collaborative Innovation Research Centre for Environment-Friendly Materials and Structures in Civil Engineering, Southeast University.

\section{Literature References}

[1] P.N. Ezhilarasi, P. Karthik, N. Chhanwal, C. Anndharamakrishnan: Food. Bioprocess. Tech. Vol. 6(3) (2013) p. 628-647.

[2] B.G.D Geest, S.D. Koker, G.B. Sukhorukov, O. Kreft, W.J. Parak, A.G. Skirtach, J. Demeester, S.C.D. Smedt, W.E. Hennink: Soft. Matter.Vol 5(2) (2009) p. 282-291.

[3] B. Hack, H. Egger, J. Uhlemann, M. Hernriet, W. Wirth, A.W.P Vermeer, D.G. Duff: Chem. Ing. Tech. Vol 84(3) (2012) p. 223-234.

[4] A. Drochon: Eur. Phys J. Appl. Phys. Vol 22(2) (2003) p. 155-162.

[5] C.Y. Gao, E. Donath, S. Moya, H. Möhwald: Eur. Phys. J. Vol. 5(1) (2001) p. 21-27.

[6] J. Sleep, D. Wilson, R. Simmons, W. Gratzer: Biophys. J. Vol 77(6) (1999) p.3085-3095.

[7] K. Chang, W. Olbricht: J. of Fluid. Mechanics. Vol. 250(2) (1993) p. 609-633.

[8] V.V. Lulevich, I.L. Radtchenko, G.B.S. And, O. Vinogradova: J. of Phys. Chem. B Vol. 107(12) (2006) p. 2735-2740.

[9] Z. Zhang: J. of Microencapsul. Vol. 16(1) (1999) p. 117-124.

[10] K. Kim, J. Cheng, Q. Liu, X. Wu, Y. Sun: J. of Biomed. Mater. Res. Part A Vol. 92A (1) (2010) p. 103-113.

[11] X. Wang, P. Sun, N. Han, F. Xing: Mater. Vol. 10(1) (2017) p. 20-38.

[12] S. Lukasiewicz: Q. J. of Mechanics. \& Appl Mathematics. Vol. 20(3) (1967) p. 293-305.

[13] E. Reissner: J. of Mathematics \& Phys. Vol. 25(1-4) (1946) p. 80-85.

[14] A.V. Pogorelov: Bendings of Surfaces and Stability of Shells. [M]. American Mathematical Society. (1988). 